\title{
City Cycling Spaces for Welcoming and Engaging All Ages
}

\section{Authors}

Tim Jones, PhD. and Ben Spencer, PhD.

Faculty of Technology, Design and Environment

School of the Built Environment

Oxford Brookes University, UK

This chapter reviews ways in which cycling spaces can be designed to provide family-oriented, community-building social and physical activity as well as an additional mode of transportation.

\section{Introduction}

There is a general consensus that cycling should be promoted as healthy and sustainable mobility. The major trend over the last half-century across many countries, however, has been towards a decline in cycling for everyday local transport.

We describe how the concept of Intergenerational Cycling Zones could help engage younger and older generations to work together to develop more civilized, harmonious and inclusive cycling environments that enable cyclists of all ages and abilities to use bicycles with ease and to interact with each other positively. Finally we discuss potential facets of Intergenerational Cycling Zones and the challenges to their acceptance within the UK context.

\section{Background}

The majority of the UK population seldom engages with cycling in any form - around two-thirds of the population use cycles less than once a year or never (UK Department for Transport, 2018). Cycling for transport in the UK, with the exception of some cities including Cambridge, Oxford and York, is unusual. What over half a century ago was a major mode of urban mobility has today become a very minor one. Cycling now accounts for only $2 \%$ of all trips and $1 \%$ of all distance travelled in the UK (ibid.). Cycling is also becoming less significant for people in achieving recommended levels of physical activity ${ }^{1}$. Between 1995 and 2010 the average time spent cycling declined from 6 hours to 5 hours per person per annum (UK Department for Transport, 2011 ${ }^{\text {a) }}$.

The share of journeys made by bicycle in the UK is low but particularly low for older age groups. There is also gender disparity with older men twice as likely to cycle as older women (UK Department for Transport, 2018). Only 1 per cent of all journeys made by people aged 65 and above in the UK are by bicycle compared to 9 per cent in Germany, 15 per cent in Denmark and 23 per cent in the Netherlands (Pucher \& Buehler, 2012). Older people's cycle journeys are typically shorter and more localized than younger adults' and are more likely to be for personal business or social purposes as opposed to commuting (UK Department for Transport, 2011 ${ }^{\mathrm{b}}$ ).

\footnotetext{
${ }^{1}$ Public Health England advises that adults aged between 16 and 65 should be at least moderately active for 150 minutes per week (Public Health England, 2014).
} 
The main reason that puts people off cycling in the UK, and particularly older people, is the perception that cycling on roads dominated by large numbers of fast-moving motorized vehicles is dangerous (Pooley et al., 2013). Older 'empty nester' householders generally have more leisure time and potential to rediscover cycling but they are inhibited from doing so because of concerns about traffic danger and also personal fitness levels and ability. Indeed, nearly half of older people feel it is difficult for them physically to cycle and only one in five are confident cycling on the roads (UK Department for Transport, 2011'). There is potential to engage older people in cycling if these concerns were addressed as 42 per cent say they would cycle more if there were more dedicated cycle paths (ibid.)

\section{The Marginalization of Cycling in the UK}

UK mobility culture has been shaped by mass car ownership which in turn has shaped how the transport system has evolved under a paradigm that has fueled faster and longer distance travel (Banister, 2008). Car use is now the norm and is convenient and considerably safer than half a century ago whereas cycling has become less convenient, less comfortable, less safe and therefore less desirable. This is because to cycle in UK cities more often than not involves negotiating space shared with cars and larger motor vehicles. The fact that many people do not even contemplate cycling is unsurprising given that the transport system has focused historically around ensuring safe passage and smooth flow of motor traffic.

Cycling for general mobility in the UK is now restricted to a minority of mostly committed cyclists or those who have little choice but to cycle for economic reasons. The remainder of the population eschews cycling or at best engages in occasional cycling for leisure in green and quiet space away from motor traffic on a weekend. This is despite a strong desire by older cyclists to share, encourage and enjoy cycling with younger generations (Jones et al. 2016). This serves to consolidate the belief that to drive in the city is 'normal' and to cycle is somehow 'abnormal', even for short journeys where cycling would be the most sensible option. Cycling therefore continues to become marginalized and cyclists on city streets are regarded as a 'nuisance'.

Those who continue to cycle in most UK cities today are typically young, male, white, 'hardened' cyclists. They are the product of a predominantly car based system that marginalizes cycling and creates an expectation that the performance of cycling requires riding quickly and assertively adorned in special protective gear. This type of 'vehicular cycling' underpinned by the notion that, 'cyclists fare best when they act and are treated as drivers of vehicles' (see Forester, 1994), often looks more like sport cycling than an ordinary method of moving around the city - see YouTube 'Effective Cycling excerpt' for example. The perpetual acclimatization to current hostile (vehicular) cycling conditions has shaped UK cycling identity and practice so-much-so that in the process of 'being a cyclist' committed cyclists often struggle to understand why more people do not cycle. Paradoxically, narratives on the advantages of cycling are often accompanied by tales of experiences of accidents and 'near-misses' (Aldred \& Crosweller, 2015); this inadvertently perpetuates the identity of a 'cycling elite' (Steinbach et al. 2011) and indeed in some cases as miscreants behaving as 'kamikazes' (Hanson, 2015). 
The picture then is of one where the emphasis is on promoting cycling safety through riders taking responsibility for their own protection (cf. helmet wearing) within a predominantly car-based transport system. The lack of progress in creating a comprehensive cycling system similar to those experienced in other northern European cities stymies any hope of intergenerational cycling. A more diverse landscape for cycling which embraces all ages and abilities is clearly needed. We now turn to some strategies for moving in this direction.

\section{Towards UK Intergenerational Cycling Zones}

Established "cycling cities" such Amsterdam (NL) and Copenhagen (DK) have a long heritage of planned interventions for cycling at both city and national level that provide conditions for intergenerational cycling. Other cities across Europe beginning to reallocate space for cycling include Munich (DE), Malmo (SE), Bordeaux (FR) and Seville (ES). So how could intergenerational cycling in the UK be achieved? Fundamentally, to encourage more cycling in urban areas requires adapting current infrastructure to provide people with the choice to be able to cycle in a safe, comfortable and inclusive environment. A number of actions will help to achieve this. The reallocation of road space from motor vehicle use to create space for cycling and walking is a key first step as set out in Cycling UK's Space for Cycling Campaign (Cycling UK). This would include local interventions in residential areas such as slower speed zones and Home Zones or Woonerfs (re: Streets). These balance the needs of residents to use streets as social spaces, with the need for vehicular traffic access such that street space is not dominated by fast moving through-traffic and parked cars. It makes possible the growth of cycling as a family-oriented recreational and practical activity in people's neighborhoods and by linking to a wider cycle-friendly network.

Traffic speed reduction and dedicated cycle space is required on busier urban roads, particularly arterial routes into towns and cities. These roads are usually the most direct routes to places in urban centers that people wish to travel to but are also themselves frequently the location for many of the services and facilities people wish to access, such as shops, health and education centers and parks. Providing sufficiently wide consistent and continuous dedicated cycle paths also enables safe and social side-by-side cycling along these roads by different generations together. These approaches are being tested in parts of London through the Mini-Holland program. This aims to encourage a more diverse range of people to cycle more safely and more often through provision of better streets and places that encourage positive social interaction - see box 'London's Mini-Holland Programme'. 


\section{London's Mini-Holland Programme}

Transport for London's (TfL) Mini-Holland programme aims to improve streets and public areas along a network of cycle routes as part of the Mayor of London's Healthy Streets agenda (TfL, 2017). In 2013, 18 outer London boroughs were invited to apply for funding from the Mayor of London's 'Mini-Hollands fund'. The boroughs of Enfield, Kingston and Waltham Forest were successful and each was awarded a total of 30 million UK pounds to complete their Mini-Holland programme by the end of 2021.

The Waltham Forest Mini-Holland programme is perhaps the most advanced and is made up of 13 schemes. It has the bold aim of getting $100 \%$ of the population cycling $10 \%$ of the time instead of only $10 \%$ cycling $100 \%$ of the time (Waltham Forest Council, 2017). The programme adopts a holistic approach to street management which includes dedicated space to cycle along busier roads that also offers physical protection from motor vehicles; measures to ensure residential streets are more appealing and safer for all; and, enhancements to public space that provide more attractive places for social interaction. Complementary programmes include cycle training, cycle road shows, bike maintenance courses, cycle hubs and cycle parking. The borough has also produced a Design Guide providing detailed information on developing 'safer and more expansive infrastructure for people on bikes, children's scooters and pedestrians' (p4) (Waltham Forest, nd.)

The potential benefits of the anticipated uptake of cycling (and walking) among residents of different ages, abilities and background are manifold. These include improved health and fitness of residents, improved air quality associated with a reduction in motor traffic, and a boost to the local economy due to increased 'footfall' for existing businesses owing to improvements to the public realm. Early evidence shortly after schemes were implemented appears to demonstrate positive trends towards more cycling and walking and associated improvements in public health. For example, Aldred et al. (2018) demonstrate that Waltham Forest Mini-Holland programme has had a positive impact on cycling and walking activity and perceptions of the local cycling environment. Meanwhile, Dajnak et al. (2018) have predicted that five-year-olds born in 2013 in Waltham Forest would each live on average for an extra six weeks as a result of the Waltham Forest Mini-Holland programme, and furthermore, the borough's 265,000 residents would gain a total of 41,000 years of extra life if air quality continues to improve because of the fall in traffic in residential areas. Further research will undoubtedly need to investigate the extent to which such spaces are also providing family-oriented, community-building, social and physical activity, but so far, the signs are positive.

Insert Figure 1 - about here

Insert Figure 2 - about here

Through widespread implementation of Mini-Holland type measures across the UK people of all ages can be encouraged to cycle together and experience positive intergenerational social interaction. There is also need to promulgate the notion of a 'generationally intelligent city' (Biggs \& Carr, 2015, p. 108). This concept moves beyond the 'working age city' and recognizes that, 'each generational group will have life projects, 
arising from the point they have reached in their life course, which give rise to distinctive requirements of urban space' (ibid). There are implications here for advocates of cycling and committed cyclists who cherish the ability to travel at speed around UK city streets. This fast 'vehicular' cycling in cities is often at the cost of more sedate cycling for all age groups and capabilities. A generationally intelligent use of space will ensure that planning and design does not cater for one type at the expense of the other although compromises will need to be made among 'speedier' cyclists that may require a rethink on the performance of cycling and expectation of travel time.

There is a need to avoid falling into the same trap that purveyors of autopia fell into in the 1960s where the desire for speed and unfettered automobility was often at the expense of quality and civilized urban space. Expectations of cycle speed will need to be addressed that recognize that cycling is not simply about getting from $A$ to $B$ as fast as possible, but also about the reliability of the journey time and the positive social and sensory experience along the way that can make cycling a more desirable activity. Participants in a study of older people's cycling in the UK reported the negative impacts of the behavior of some younger cyclists (Jones et al. 2016). This included the perception that they cycle too fast in city streets and pass too close to other riders. Participants explained their own attempts to cycle in a civilized way by leaving sufficient journey time and interacting with other road users in a courteous and considerate manner.

Enhancing the quality of experience of riding through the city will be important in garnering appreciation of the need to think beyond simple speed. This could be achieved through concerted campaigns promoting a vision of civilized (and not competitive) 'smoother cycling' for young and older alike. It will require a move away from a single 'cycling identity' towards multiple and diverse identities of bicycle users (Handler, 2014). The creation of safe, comfortable spaces for cycling would not require high levels of cycling capability and vigilance. A more forgiving and relaxed environment would enable greater appreciation of the wider surroundings whether historic architecture or the social 'street ballet'. The provision of smooth, consistent surfaces is of course fundamental in allowing riders to be able to look-up and appreciate their local surroundings rather than being fixated on road conditions below their wheels. Finally, in order to enhance the aesthetic experience of cycling in urban areas, the urban design profession needs to apply the same attention to cycling as it currently does to walking and ensure that this is not left to the purely functionalist tendency within traffic engineering (Forsyth \& Krizek, 2011).

\section{Conclusion}

We have outlined how Intergenerational Cycling Zones could be created in the UK that enable more civilized, harmonious and inclusive cycling by all ages. This would create towns and cities that 'are more than simply rat-runs between centers of work, consumption and closed door domesticity' (Biggs \& Carr, 2015, p.108). It implies an abandonment of the current focus on training and improving the capability of riders to survive a system developed for the motor-vehicle. Instead we argue for fundamental change to the system to provide greater spatial justice for all ages and types of cyclist. This has the potential to break down ageist social norms about who can and should cycle, reduce social isolation, and ensure the safety of vulnerable members of the community. Intergenerational Cycling Zones would not only improve connections to activities within neighborhoods and across towns and cities but also make the experience of cycling enjoyable and sociable, therefore providing greater opportunity for active living and positive social contact for all. 


\section{References}

Aldred, R., Croft, J., \& Goodman, A. (2018). Impacts of an active travel intervention with a cycling focus in a suburban context: One-year findings from an evaluation of London's in-progress miniHollands programme. Transportation Research Part A: Policy and Practice. (article in press)

Aldred, R. \& Crosweller, S. (2015). Investigating the rates and impacts of near misses and related incidents among UK cyclists. Journal of Transport \& Health, Volume 2, 3, 379-393.

All Parliamentary Cycling Group (2013). Get Britain Cycling: Summary \& Recommendations. APCG. Banister, D. (2008). The sustainable mobility paradigm. Transport Policy, 15, 73-80. doi:10.1016/j.tranpol.2007.10.005

Biggs, S. \& Carr, A. (2015). Age- and Child-Friendly Cities and the Promise of Intergenerational Space, Journal of Social Work Practice, 29:1, 99-112. doi:10.1080/02650533.2014.993942

CyclingUK. Space for Cycling Campaign. Available at: https://www.cyclinguk.org/campaign/spacefor-cycling [Accessed on 23 January 2019]

Dajnak, D. Walton, H. Gregor, S. Smith, J.D. Beevers, S. (2018) Air Quality: concentrations, exposure and attitudes in Waltham Forest. Environmental Research Group, School of Analytical, Environmental and Forensic Sciences, King's College London. Available at: https://walthamforest.gov.uk/sites/default/files/WalthamForest Kings\%20Report 310718.pdf

Forester, J. (1994). Bicycle Transportation: A Handbook for Cycling Transportation Engineers. USA: MIT Press.

Forsyth, A., \& Krizek, K. (2011). Urban Design: Is there a Distinctive View from the Bicycle? Journal of Urban Design, 16, 531-549.

Handler, S. (2014). A Research \& Evaluation Framework for Age-friendly Cities. UK Urban Ageing Consortium: Stoke-on-Trent. Available at: https://www.ageing-better.org.uk/publications/researchevaluation-framework-age-friendly-cities [Accessed 11 April 2019]

Hanson, M. (2015) Still Here: reflections on later life - cycling. I want to be nice to cyclists - but I'm sick of kamikazes. The Guardian Mon 9 November 2015. Available at:

https://www.theguardian.com/lifeandstyle/2015/nov/09/cyclists-urban-bikes-kamikaze-safetypedestrians [Accessed 23 January 2019].

Jones, T. Chatterjee, K. Spinney, J. Street, E. Van Reekum, C. Spencer, B. Jones, H. Leyland, L.A. Mann, C. Williams, S. \& Beale, N. (2016) cycle BOOM. Design for Lifelong Health and Wellbeing. Summary of Key Findings and Recommendations. Oxford Brookes University UK.

Pooley, C., Jones, T., Tight, M., Horton, D., Scheldeman, G., Mullen, C., Jopson, A., Strano, E. (2013). Promoting Walking and Cycling: New Perspectives on Sustainable Travel. Bristol, UK: Policy Press.

Public Health England (2014). Everybody Active Everyday: An Evidenced Based Approach to Physical Activity. London: PHE. 
Pucher, J. \& Buehler, R. (2012). City Cycling. Cambridge MA: MIT Press.

re:Streets. Home Zone Case Studies. Available at https://www.restreets.org/case-studies/homezones [Accessed 23 January 2019]

Steinbach, R., Green, J., Datta, J., \& Edwards, P. (2011). Cycling and the city: A case study of how gendered, ethnic and class identities can shape healthy transport choices. Social Science \& Medicine, 72, 1123-1130. https://doi.org/10.1016/j.socscimed.2011.01.033

Transport for London (TfL) (2017) Healthy Streets for London Prioritising walking, cycling and public transport to create a healthy city. Available at: http://content.tfl.gov.uk/healthy-streets-forlondon.pdf [Accessed 28 January 2019]

UK Department for Transport (2018). Transport Statistics Great Britain. London: DfT.

UK Department for Transport (2011ª). National Travel Survey 2010. London: DfT.

UK Department for Transport (2011 ${ }^{\text {b }}$. National Travel Survey 2008-2010. London: DfT.

UK Department for Transport $\left(2011^{c}\right)$. Climate change and transport choices: segmentation study final report. London: DfT

Waltham Forest Council (nd.) Waltham Forest Mini-Holland Design Guide. Available at: https://www.enjoywalthamforest.co.uk/wp-content/uploads/2015/01/Waltham-Forest-MiniHolland-Design-Guide.pdf

Waltham Forest Council (2017) About Mini Holland. Available at https://www.enjoywalthamforest.co.uk/about-mini-holland/[Accessed 29 January 2019]

YouTube Effective Cycling Excerpt. Available at https://www.youtube.com/watch?v=5leVR-xnk6g [Accessed 23 January 2019].

Published in:

Intergenerational contact zones: Place-based strategies for promoting social inclusion and belonging (ISBN: 9780367189020) / edited by Matthew Kaplan, Leng Leng Thang, Mariano Sánchez, Jaco Hoffman. doi: https://doi.org/10.4324/9780429199097 